\title{
Human Resources Risk Element Transmission Model of Construction Pro- ject Based on System Dynamic
}

\author{
Li Cunbin, Liu Yunqi* and Li Shuke
}

School of Economics and Management, North China Electric Power University, Beijing, 102206, P.R. China

\begin{abstract}
Human resources risks lead to undermine project performance, however, due to complex and flexible characteristic of the human resources risks, the prediction and control of risks resulting from human resources is more difficult than other risk factors. In order to achieve effectively construction goal, based on the generalized project risk element transmission theory and system dynamics, a system dynamics model of human resources risk element transmission during construction projects was developed, which analyzed different influence results that human resources risks of different time and different level caused and dynamic transfer process of human resources risk elements. Firstly, the restoration process of human resources can significantly delay project duration after human resources risk occurrence. Secondly, in the run of project construction, asymmetric composition of human resources can create unsaturation of real workload, which caused inefficiency of human resources. Finally, during different time that human resources occur, different measures which employed either increase numbers of human resources to speed up construction or no increase human resources result in delay of project duration will seriously influence project cost. Moreover, the case study makes a more particular knowledge of human resources risk elements transmission to quantitative description of project duration and cost. This model can provide important information for risk managers and project managers addressing human resources risk.
\end{abstract}

Keywords: Construction project, human resources risk, risk element transmission, risk management, system dynamic.

\section{INTRODUCTION}

Only from following information indicates that a mass of duration delays and cost overruns exist in worldwide construction projects in spite of advances in construction equipment and management techniques [1-5]. There are 20 civil infrastructure projects across 17 states experienced significant cost overruns ranging from around $40 \%$ to $400 \%$ in the United States and only $70 \%$ of projects in the United Kingdom were delivered within $5 \%$ of the tender cost and only $38 \%$ within $5 \%$ of the tender program and only one-eighth of Australian building contracts were completed within the scheduled completion dates and that the average schedule overrun exceeded $40 \%$ [6-8]. Many researches have focused on universality of the problem of schedule delays and cost overruns, wherein, Flyvbjerg et al. concluded that cost overruns were found in $90 \%$ of these projects and that such phenomenon has persisted over the past 70 years by analysis of 258 mega- projects undertaken across 20 countries [9]. Meanwhile, there are literatures proposed various causes and solution of addressing schedule delays and cost overruns, especially Reason contends that it is often the most qualified and highly competent individuals that commit errors with the most detrimental consequences [10].

In the field of project risk management, lots of different models, tools and techniques were studied and used [11].
Kash Barker proposed a quantitative risk analysis framework to measure the sensitivity of the consequences of extreme events to uncertainty parameters of the basic probability distribution [12]. This approach avoided human influence factor in expert assessment method, and had a good effect on risk decision making. Alejandro Balbás transformed the risk function into an infinite-dimensional Banach space of linear programming, and gave the general simplex algorithm [13], which made good application in investment portfolio and the optimal hedge. Other methods such as artificial neural networks [14], genetic algorithms [15], Monte Carlo simulation [16], risk assessment [17] and multi-agent [18] were used to solve the project risks problems.

However, as a complex system, construction projects consist of various factors that influenced schedule delays and cost overruns, aforementioned methods may not enough to describe its reciprocal and looped relationships and how such relationships emerge and interact with one another and dynamic evolution process $[19,20]$. System dynamics (SD) is a popular approach to study such problems for its ability to deal with high levels of uncertainty, causal ambiguity and modelling approach which describes how systems evolve over time since it is introduced by Forrester in the early 60 's as a modeling and simulation methodology for long-term decision-making in dynamic industrial management problems [21-23].

Much work has been done on the research of risk management and the related theories are mature, but the research on risk element transmission in projects is not enough. $\mathrm{Li}$ Cun-bin defined the basic risk variables as risk element, and 
proposed that the project objectives (such as period, cost) often fluctuate with the random fluctuation of risk elements. This kind of transmission is called risk transmission [24]. Furthermore, a three-dimensional model of generalized project risk element transmission theory was introduced [25-27], in which a risk element transmission analytical model was proposed to study the transmission impact of project period risk element.

On the basis of reference to vast literatures and huge study on construction projects, this paper considers that a major contributor to undermine project performance is human resources risk. Combined methods of SD with risk element transmission theory, this paper proposed a system dynamics model, which is based on the definition of risk element transmission influence as the model purpose and the construction cost and period as system boundary, the feedback loop of one interrelated construction projects was described, and then system dynamics was used to establish a risk analysis model. Finally, by model simulation, the results of different situations were contrasted to verify the existence of risk element and examine the effect of risk element on the object of project.

\section{THE ANALYSIS OF HUMAN RESOURCES RISK ELEMENT TRANSMISSION SYSTEM}

\subsection{Based on GSM Technology for Process Design of Ceramic Product Modeling Capabilities}

In the process of project construction, if there is no risk occurring, the entire project will be completed successfully in the control range of the planned duration and budget, as the solid line in Fig. (1) shows. When the human risk element is produced for some reason during the project construction, the human resources will lose and the constructability will reduce in some degree, then the duration will delay. If the human risk causes the loss of key staff, to assure the quality, the extra engineering quantity owing to rework is inevitable. When the problem happens, the project managers will probably increase investment to replenish the lost staff and restore the planned duration, however it is quite difficult to achieve the desired effect due to the limit of actual process and ability. As the dashed line in Fig. (1) shows, there is the evident phenomenon of cost overrun and delay at the time of completion.

\subsection{Causal Analysis of the System}

In order to reflect the process that how the human risk element has impact on the project more accurately, in this paper, the human risk element is divided into two kinds: key staff risk element and general staff risk element. Key staff mainly refers to the personnel that can have a direct impact on the quality of construction; general staff mainly refers to the personnel that can have a direct impact on the speed of it; the other personnel that indirectly impacts quality and speed has not been included into this research.

As the key staff risk element will occur at some time in the process of project construction, the proportion of the technical personnel will decline for the reason of loss and the technical capacity will not reach the necessary standards. Undoubtedly, the construction quality will be influenced at

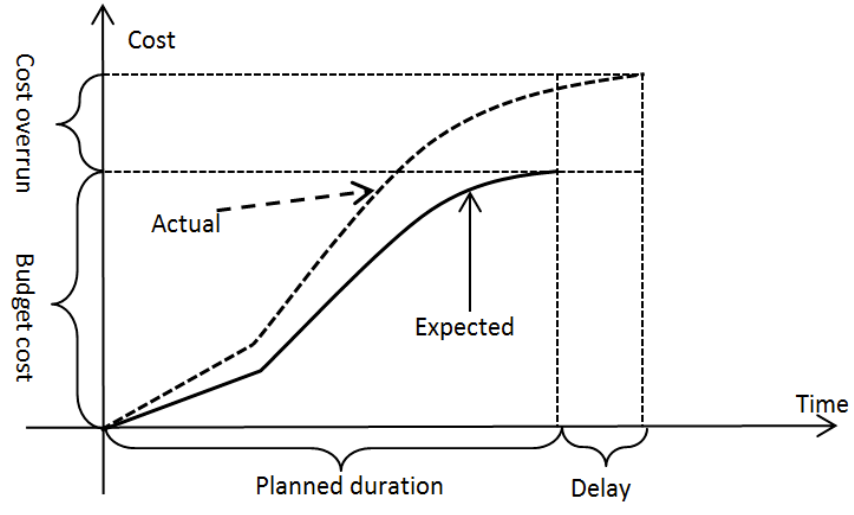

Fig. (1). Human resources risk element analysis.

this time. While the actual quality is below the acceptability criteria, the extra engineering quantity that is caused by rework will emerge. This situation will prompt the project managers to improve the construction quality, however there are further problems. Firstly, to improve the construction quality, it needs to strengthen technical capacity and to increase investment of the key staff, however this approach will accelerate the expenditure of budget; in addition, it takes a certain quantity of time to arrange these new technical personnel and to wait for them to play a true role which is able to improve the quality in the actual work, as a result that the project duration will be impacted by the phenomenon of the prior delay. Fig. (2) reflects the causal relationship of transmission of key staff risk element.

On the other hand, if the general staff risk element occurs at some time in the process of project construction, as a result of their loss, the constructability will decline and the construction speed will slow. Then the problem that whether the remaining engineering can be completed on the planned duration emerges. When the project managers are under the deadline pressure, to improve constructability, they tend to enhance the construction speed according to the remaining engineering and deadline pressure. Analogously, there also exist two issues. Firstly, to improve the constructability, it needs to devote more construction personnel, and this will accelerate the expenditure of budget; furthermore, it takes a certain quantity of time to arrange these new general personnel and to wait for them to play a true role who is able to accelerate the speed in the actual work, likewise, as a result that the project duration will be impacted by the phenomenon of the prior delay. The causal relationship of transmission of general staff risk element is exhibited in Fig. (3).

After the risk identified, in order to complete the project the expected duration, a part of project managers would take the approach of working overtime into consideration. The situation corresponding to working overtime has been studied in the literature [13], therefore, only the phenomenon of delay resulting from the new devotion of human resource will be considered in this paper.

\section{SYSTEM DYNAMICS MODELING}

A dynamic construction model based on system dynamics (SD) can be established to quantitatively analyze the effect of the human resource risk element transmission. The 


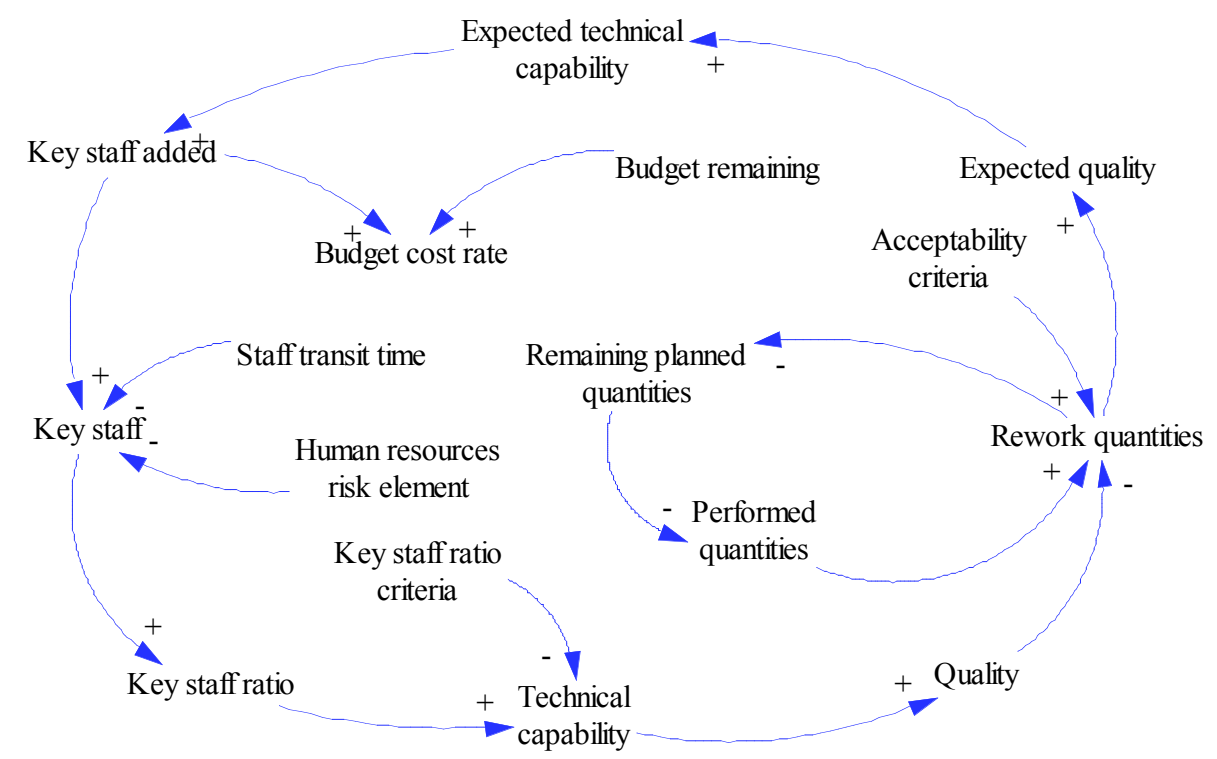

Fig. (2). Key staff risk causal loop diagram.

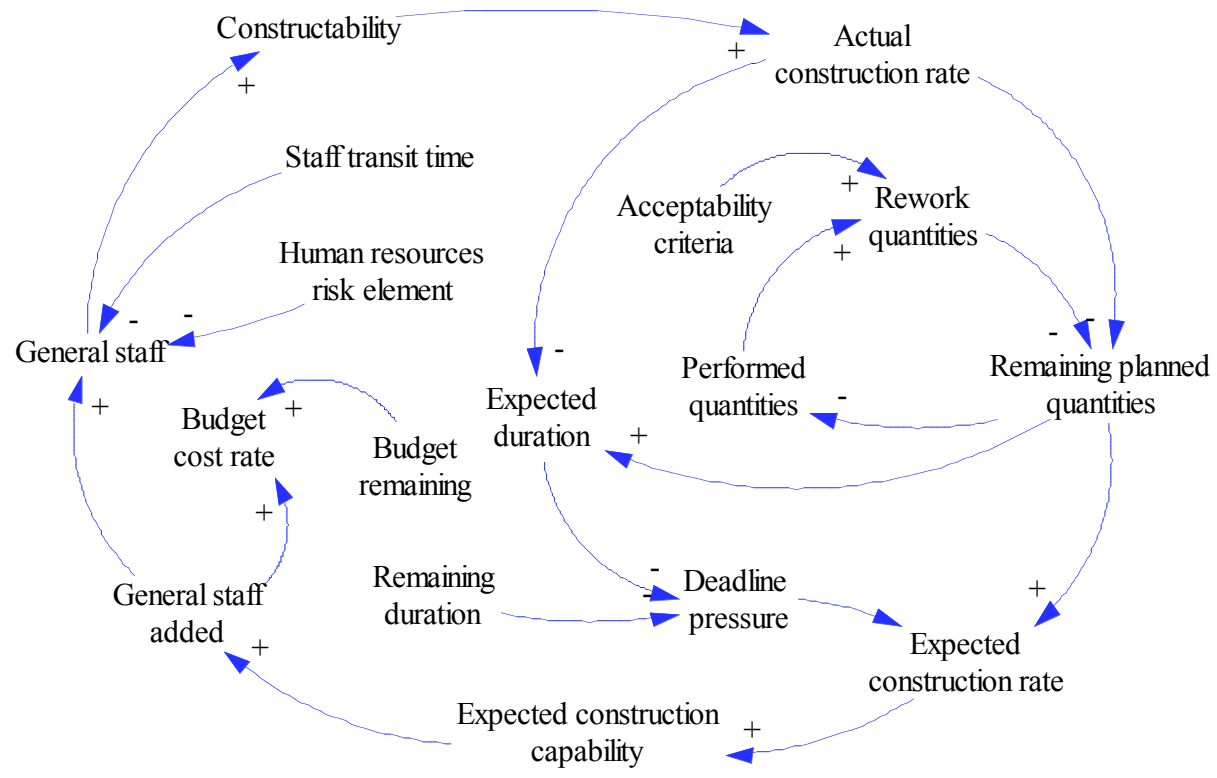

Fig. (3). General staff risk causal loop diagram.

main SD software used to build model include iThink, PowerSim and Vensim. In the paper, software of Vensim was used to build a model shown as Fig. (4).

The model includes six subsystems composed by 57 variables. In the following, a part of main functional formulae are described.

\subsection{Key Staff Risk Subsystem}

The model of key staff risk subsystem is exhibited by the lower left part in Fig. (4). In this subsystem, the human risk element occurs at the moment of Y1. The key staff risk element refers to the proportion of the loss of key staff. When the loss of technical makes the construction quality decline, the project managers usually choose to invest new key staff into construction. Here is the expression of the investment rate of key staff.
Key staff in rate $=$ IF THEN ELSE (Remaining planned quantities $>0$, IF THEN ELSE (Key staff + New key staff + General staff in rate+ General staff + New general staff $<>0$,IF THEN ELSE ((Manpower Projection $>0.001$ : OR :( Expected technical capability change $>0$ : OR: Key staff ratio criteria $<>$ (Key staff + New key staff)/ (Key staff + New key staff + General staff in rate + New general staff + General staff))), IF THEN ELSE ((General staff in rate+ New general staff + General staff)*(Key staff ratio criteria/ (1-Key staff ratio criteria))-INTEGER ((General staff in rate+ New general staff + General staff)*(Key staff ratio criteria/ (1-Key staff ratio criteria) $))>0.001$, INTEGER ((General staff in rate + New general staff + General staff)*(Key staff ratio criteria/(1-Key staff ratio criteria) $)+1-$ Key staff-New key staff), INTEGER((General staff in rate+ New general staff + General staff $)^{*}($ Key staff ratio criteria/(1-Key staff ratio criteria)))-Key staff-New key staff),0),0),0) (1). 


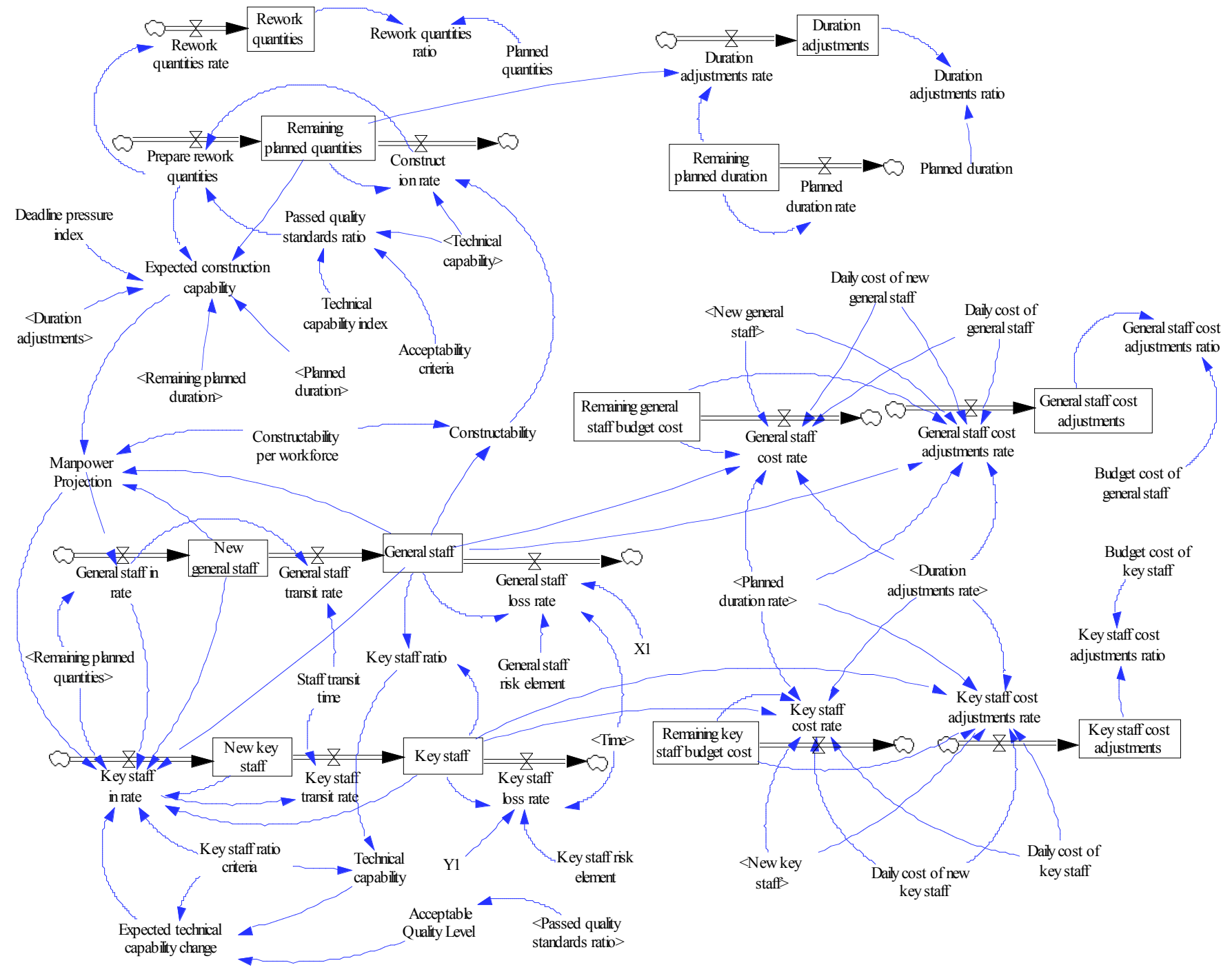

Fig. (4). Stock and flow diagram for human resources risk element transmission.

In the above formula, while remaining quantities exists, it is most important to understand the situation of human resource. If it takes place that all of the key staff and general staff are lost at the same time, new general staff should be invested first and then we can calculate the demand for key staff; if the construction speed or the proportion of key staff is below the expected criterion, to devote more general personnel or technical personnel at some point is a usual adopted measure. For the quantity of staff must be an integer, when the increased demand of key staff is a decimal, we take the smallest integer larger than the decimal into calculation in order to make the proportion of key staff above its criterion. When the staffs figure of units of thousandth in practical work, it is so small that can be ignored. Thus, the thousandth is defined as the judging yardstick. Besides, since the above procedure involves ratio calculation, the deviation generated in the calculation process need to be taken into consideration and the same below in this paper.

\subsection{Key Staff Cost Adjustment Subsystem}

The model of key staff cost adjustment subsystem can be seen in the lower right part in Fig. (4). After the human risk element is produced in the construction process, the staff structure and the planned duration will be disrupted. Then, within the duration of the project, if the remaining budget for key staff is not enough to be spent for the actual labor cost, the project managers have to make adjustment in accordance with their balance. Here is the expression of the cost adjustment of key staff.

Key staff cost adjustments rate=IF THEN ELSE (Planned duration rate $>0$ :OR:Duration adjustments rate $>0$, IF THEN ELSE(Remaining key staff budget cost $<$ Key staff*Daily cost of key staff+ New key staff*Daily cost of new key staff, Key staff*Daily cost of key staff+ New key staff*Daily cost of new key staff-Remaining key staff budget cost,0),0) (2).

\subsection{General Staff Risk Subsystem}

The model of general staff risk subsystem is shown by the middle left part in Fig. (4). The occurrence of general staff risk element means the loss of general personnel. In such a case, in order to ensure the essential construction speed, the project managers will enhance the expected constructability. The expected constructability is expressed as following. 
Expected construction capability $=$ IF THEN ELSE( Planned duration*(Deadline pressure index-1)+Remaining planned duration-Duration adjustments $<1$, Remaining planned quantities + Prepare rework quantities, (Remaining planned quantities + Prepare rework quantities)/(Planned duration*(Deadline pressure index-1)+Remaining planned duration-Duration adjustments)) (3).

In the above formula, the extended ratio of project duration is limited by the bearable threshold of deadline pressure: if the duration is less than 1 day, the project managers will expect to accomplish the required constructability within 1 day; if the duration is longer, the project managers will pretend to assign the constructability with reference to the limited time. To attain the expected constructability, the way of increasing the number of general personnel is feasible. Similarly, when the personnel number is a decimal, we choose the smallest integer larger than it to calculate. The expression of adjusted personnel demand is shown below.

Manpower Projection= IF THEN ELSE (Expected construction capability/Constructability per workforceINTEGER(Expected construction capability/Constructability per workforce) $>0.001$,INTEGER(Expected construction capability/Constructability per workforce) +1 -New general staff-General staff, INTEGER(Expected construction capability/Constructability per workforce)-New general staffGeneral staff) (4).

\subsection{General Staff Cost Adjustment Subsystem}

The model of this subsystem is described by the middle right part in Fig. (4). Like the key staff cost adjustment subsystem, the phenomenon that the staff structure and the project planned duration are disrupted will follow the situation that the human risk element is generated in the construction process. During the duration of the project, if the remaining budget for general staff is not enough for the actual labor cost, we need to make adjustment. The corresponding expression is no longer given repeatedly.

\subsection{Rework Subsystem}

The model of rework system is shown by the upper left part in Fig. (4). The key staff risk means that technical capacity cannot meet the requirement. This causes the corresponding proportion of construction quality reaching standard to fall and the amount of rework quantities to increase. The expression of proportion of construction quality reaching standard is following.

Passed quality standards ratio=IF THEN ELSE (Technical capability*Technical capability index $>$ Acceptability criteria, 1, Technical capability/Acceptability criteria*Technical capability index) (5).

In this formula, the effect value of technical capacity is set to reflect the situation how the standard of construction quality changes.

\subsection{Duration Adjustment Subsystem}

The model of duration adjustment subsystem is exhibited by the upper right part in Fig. (4). Obviously, the construction progress will be influenced along with the generation of human risk element. If the construction task will not be completed within the planned duration, then the duration would have to be adjusted. The expression of duration adjustment is following.

Duration adjustments rate $=$ IF THEN ELSE (Remaining planned quantities $>0$, IF THEN ELSE(Remaining planned duration $=0,1,0), 0)(6)$.

\section{THE ANALYSIS OF EXAMPLES}

\subsection{The Explanation of Parameter Settings}

Table 1 exhibits a part of parameter settings in the model. The values in this table are analog values of actual work. Thus, we can adjust them depending on the different project types and management mechanisms, and such behavior will not have undesirable impact on the robustness and accuracy.

\subsection{Simulation and Analysis}

\subsubsection{Simulated Result without Risk Element}

We simulate the situation that the human risk element does not occur, that is to say, both the key staff risk element and the general staff risk element are 0. This is shown in Fig. (5). The project conducts a total of 50 days, and the circumstances during this period are: the rework quantities have not been produced, and thus, construction duration, key staff cost and general staff cost do not need to be adjusted; the quantities and the above two kinds of cost are implemented as planned in the form of decreasing at an uniform speed with the result of no surplus.

\subsubsection{Simulated Result with Risk Element}

This part simulates the situation carried out to the 30th day that the key staff risk element was 1, the deadline pressure index was 1(all the technical personnel are lost), and the project did not allowed to postpone. The corresponding simulation result can be seen in Fig. (6).

During the period of the key staff losing, since the construction quality can't be guaranteed, the project managers have to stop the construction process so as not to cause a large quantity of rework quantities, and yet, the labor charge of general staff should be paid normally before the new key staff is invested; after the investing, the project managers need to increase the investment of key and general human resource for finishing workload within its planned duration, the project managers need to increase the investment of key and general human resource. The project is carried out in 50 days, and we can find out in this figure that the quantities of key personnel and general personnel reach respectively a maximum of 62 and a maximum of 612 , and the labor charges increase 0.87 of ten thousand yuan and 17.3 of it.

As shown in Fig. (7). This part simulates the situation carried out to the $48^{\text {th }}$ day that the general staff risk element is 1 , the deadline pressure index is 1 (all the general personnel are lost), and the project did not allowed to postpone. The construction was forced to stop after all general staff ran off, but the key staff's costs were paid. The time for recruit the new employee has more than the schedule and the remaining projects are few. Normally, as the project will come to an end soon, there was not much need to increase general staff in order to enhance the speed of construction. 
Table 1. List of variables.

\begin{tabular}{|c|c|c|c|c|}
\hline 1 & $\mathrm{X} 1$ & Duration & day & \\
\hline 3 & Remaining duration & {$[0, \infty]$} & day & 50 \\
\hline 5 & Budget cost & {$[0, \infty]$} & day & 12000000 \\
\hline 6 & General staff & {$[0, \infty]$} & worker & 500 \\
\hline 7 & Key staff & {$[0, \infty]$} & worker & 20 \\
\hline 8 & Daily cost of general staff & {$[0, \infty]$} & yuan/worker/day & 110 \\
\hline 11 & Daily cost of new key staff & {$[0, \infty]$} & yuan/worker/day & 60 \\
\hline 12 & Budget cost of general staff & {$[0, \infty]$} & yuan & 2750000 \\
\hline 13 & Budget cost of key staff & {$[0, \infty]$} & yuan & 400000 \\
\hline 14 & Remaining planned quantities & {$[0, \infty]$} & task & 50000 \\
\hline 15 & Staff transit time & {$[0, \infty]$} & day & 2 \\
\hline 16 & Key staff ratio criteria & {$[0,1]$} & unitless & $50 /(50+500)$ \\
\hline 17 & Acceptability criteria & {$[0,1]$} & unitless & 0.98 \\
\hline
\end{tabular}

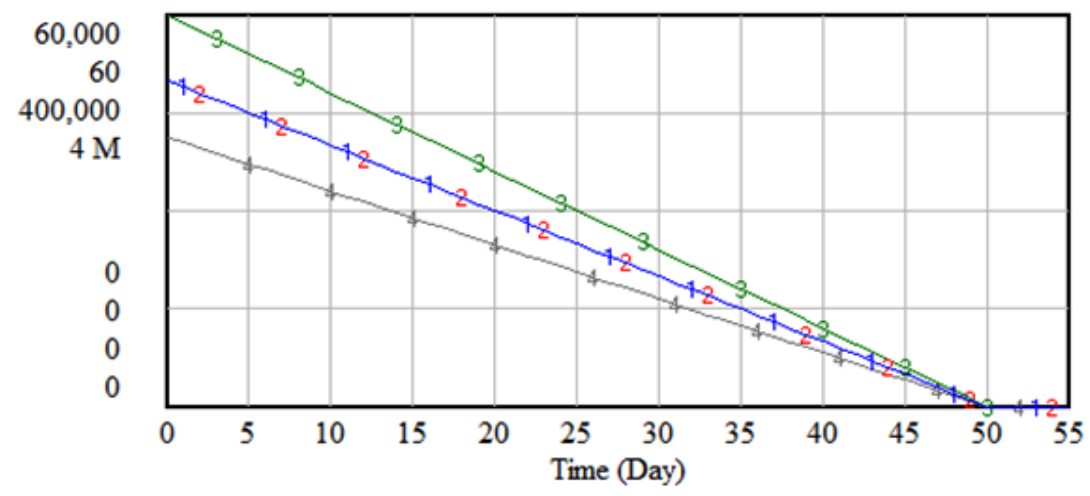

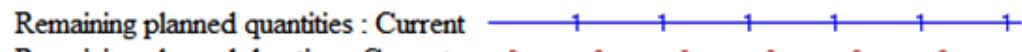

Remaining planned duration: Current $\begin{array}{llllllll}2 & 2 & 2 & 2 & 2 & 2\end{array}$

Remaining key staff budget cost : Current $\mathrm{O}$
Remaining general staff budget cost : Current

Fig. (5). Simulated result without risk element.

The project is carried out in 53 days, and the key staff costs increase 2.4 of ten thousand yuan, the general staff costs increase 5 of it too.

The Fig. (8) demonstrates that the key staff risk element and general staff risk element occurred at 30 th, and the pro- ject was not allowed to be postponed. The three parameter of the model were all set to 1 . Without key staff and general staff the construction was forced to stop. There was delay after recruiting the new employee. In order to not to delay, the project manager would enhance the speed of construction, through increase in key staff and the general staff. 

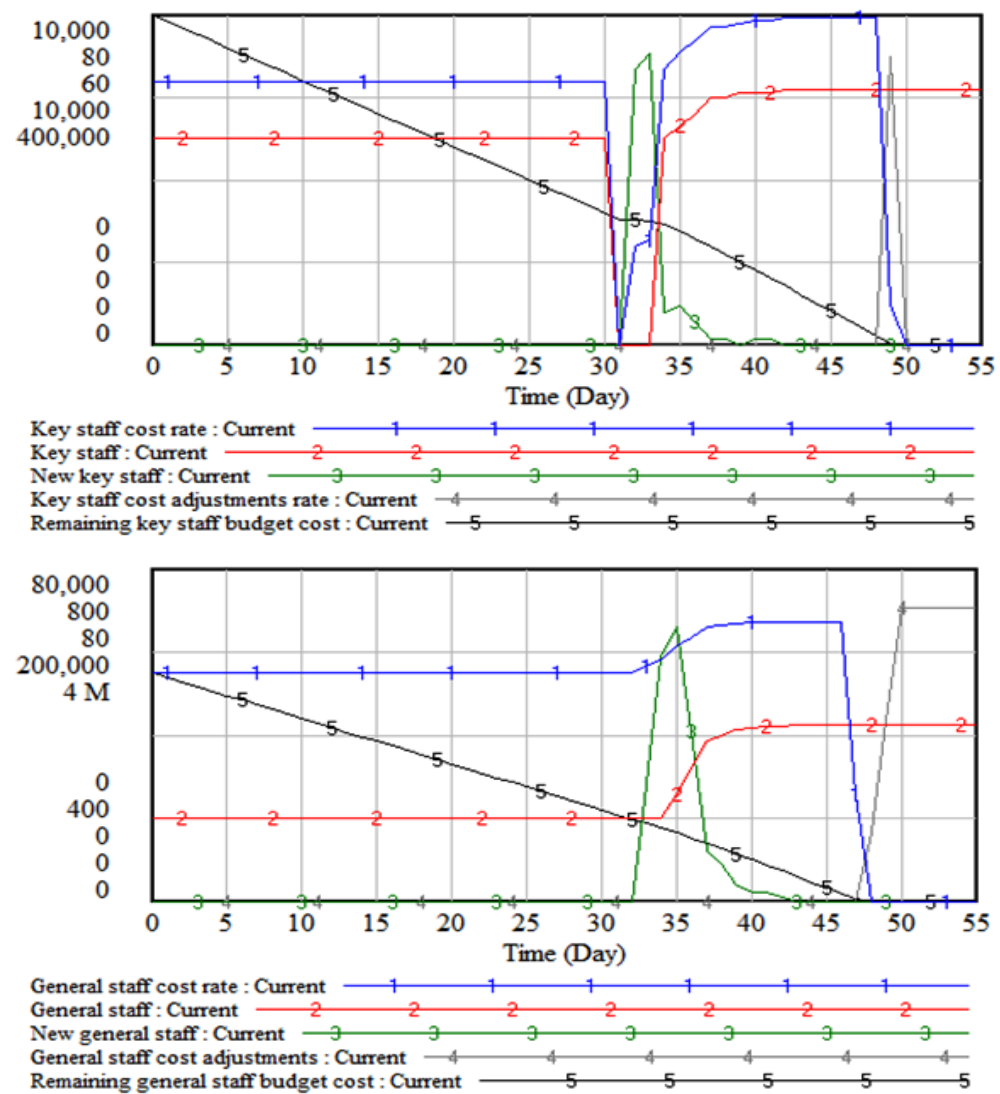

Fig. (6). Simulated result at $30^{\text {th }}$ day with key staff risk element $=1$, deadline pressure index $=1$.
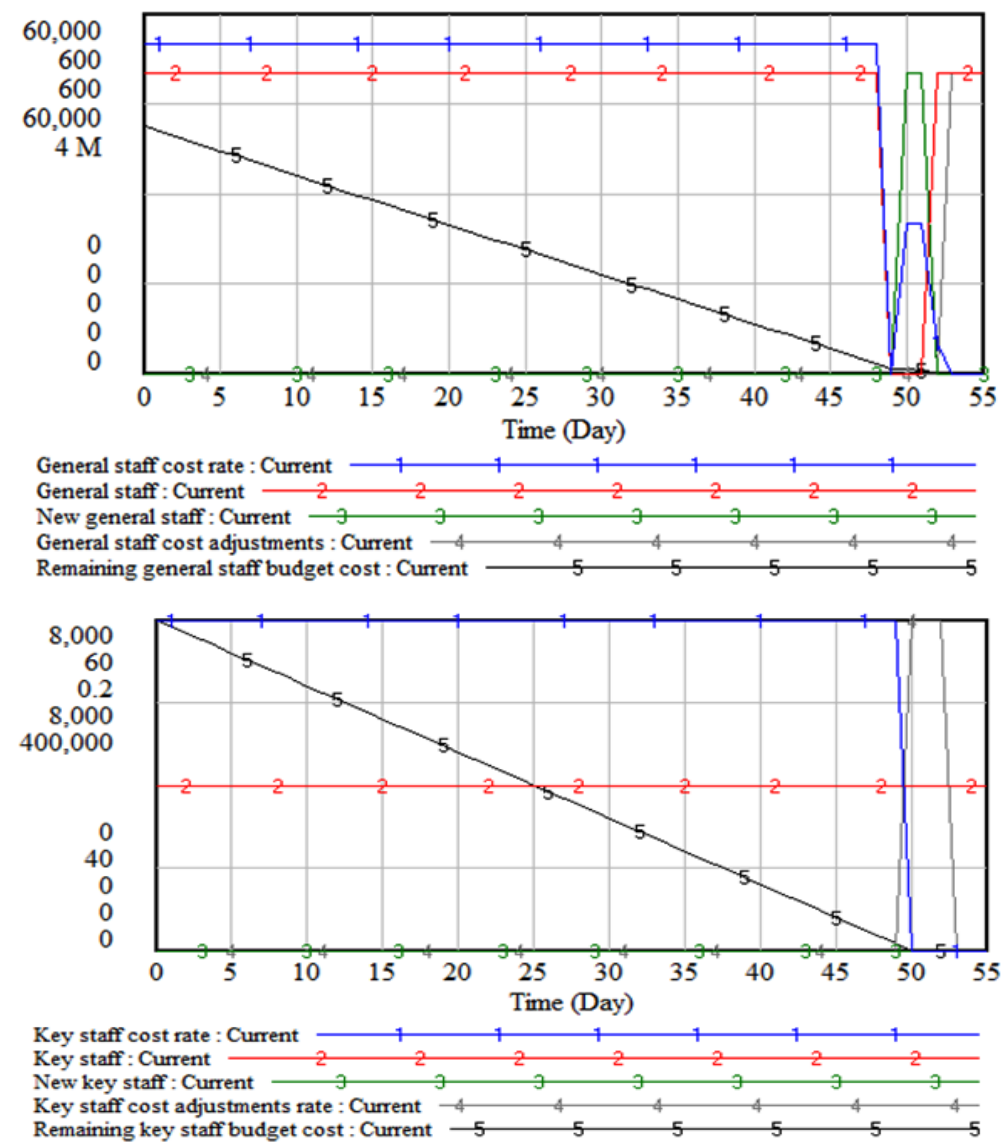

Fig. (7). Simulated result at $48^{\text {th }}$ day with general staff risk element=1, deadline pressure index $=1$. 

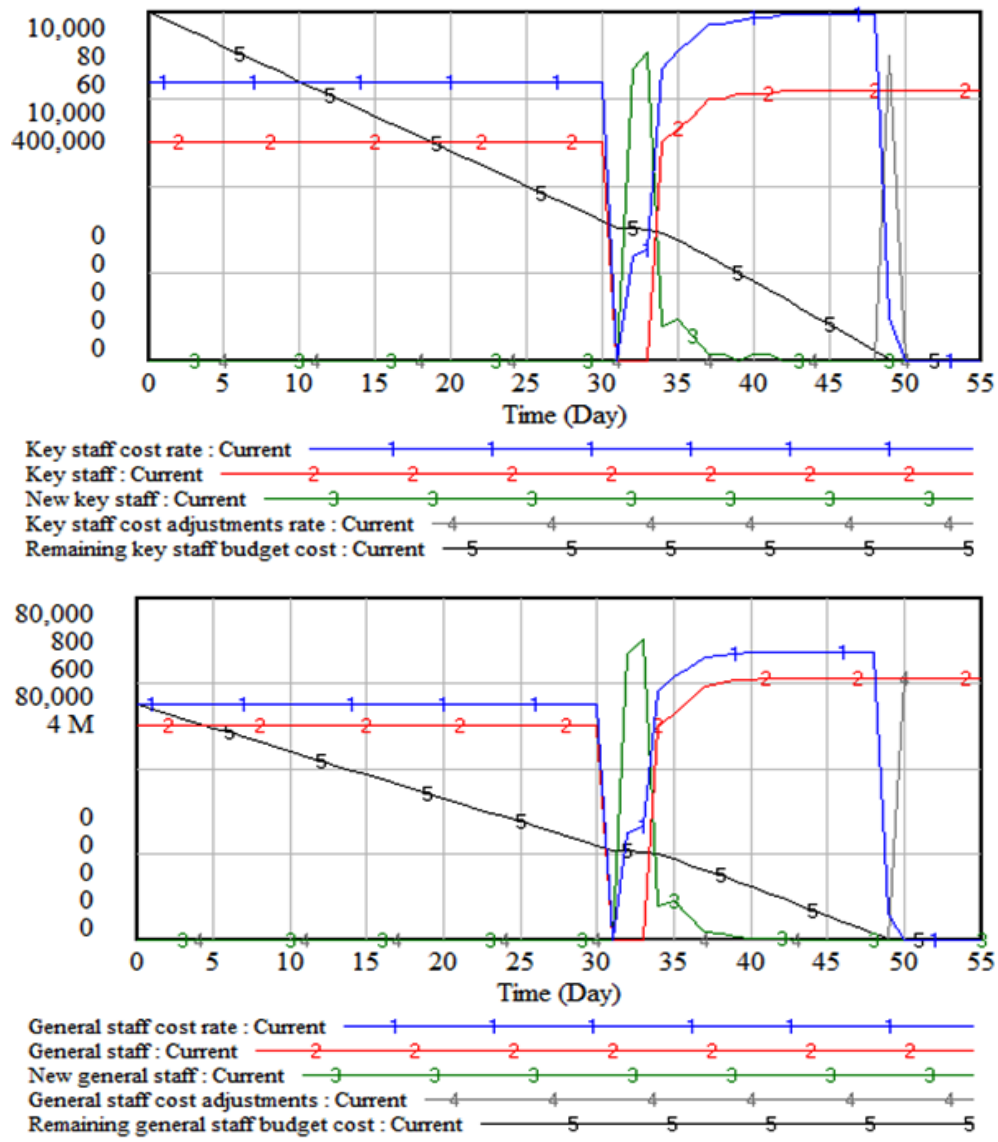

Fig. (8). Simulated result at $30^{\text {th }}$ day with key staff risk element $=1$, general staff risk element $=1$, deadline pressure index $=1$.
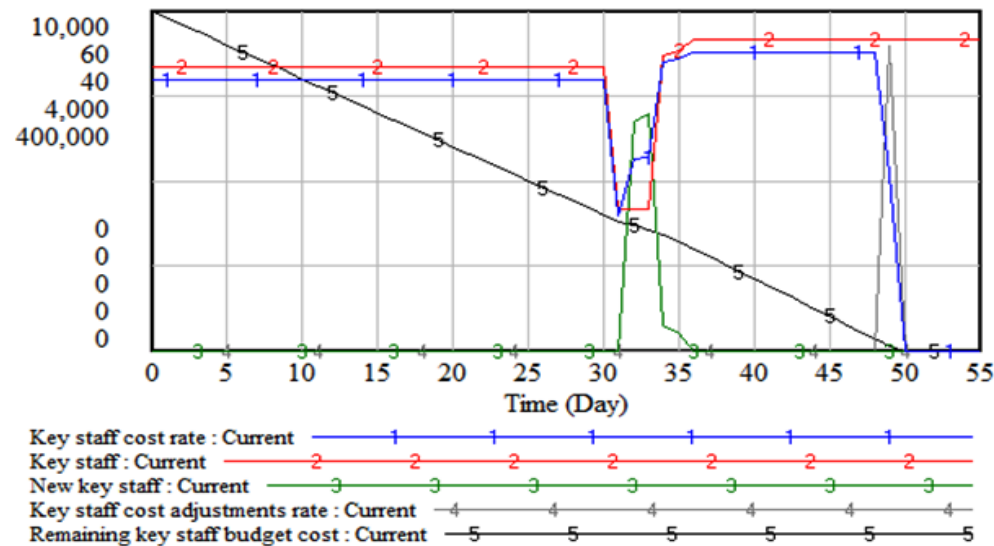

Remaining key staff budget cost : Current $\begin{array}{lllll}5 & 5 & 5 & 5 & 5\end{array}$

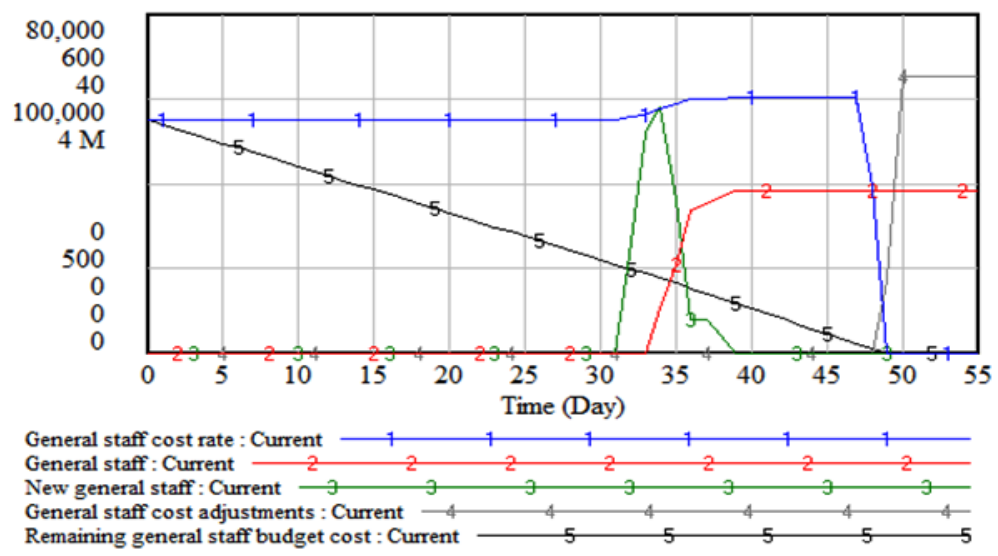

Fig. (9). Simulated result at $30^{\text {th }}$ day with key staff risk element $=0.5$, deadline pressure index $=1$. 

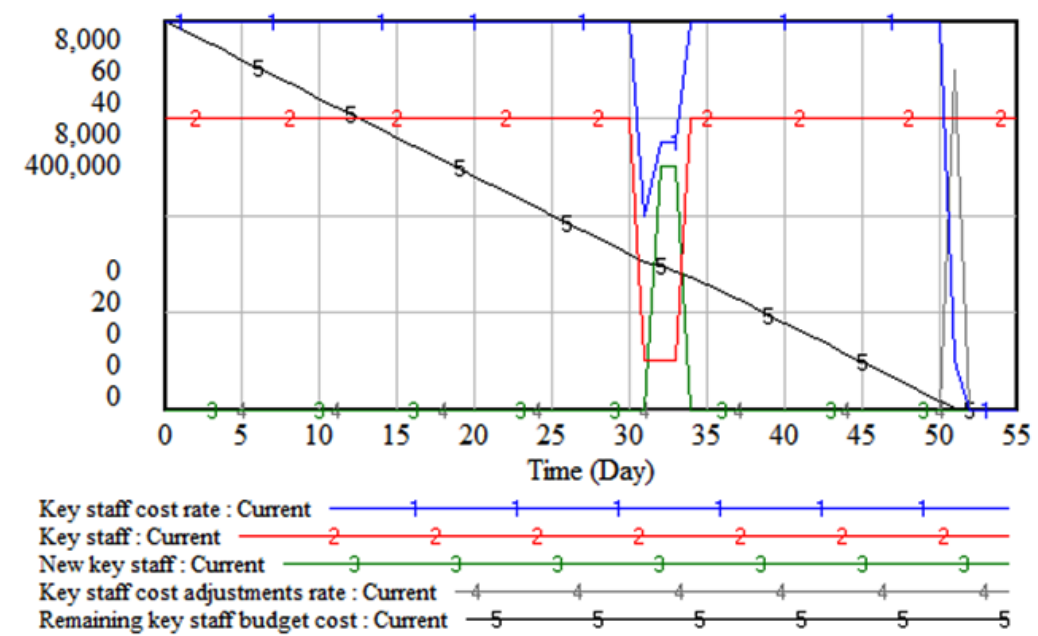

Remaining key staff budget cost : Current $\begin{array}{llllll}5 & 5 & 5 & 5 & 5 & 5\end{array}$
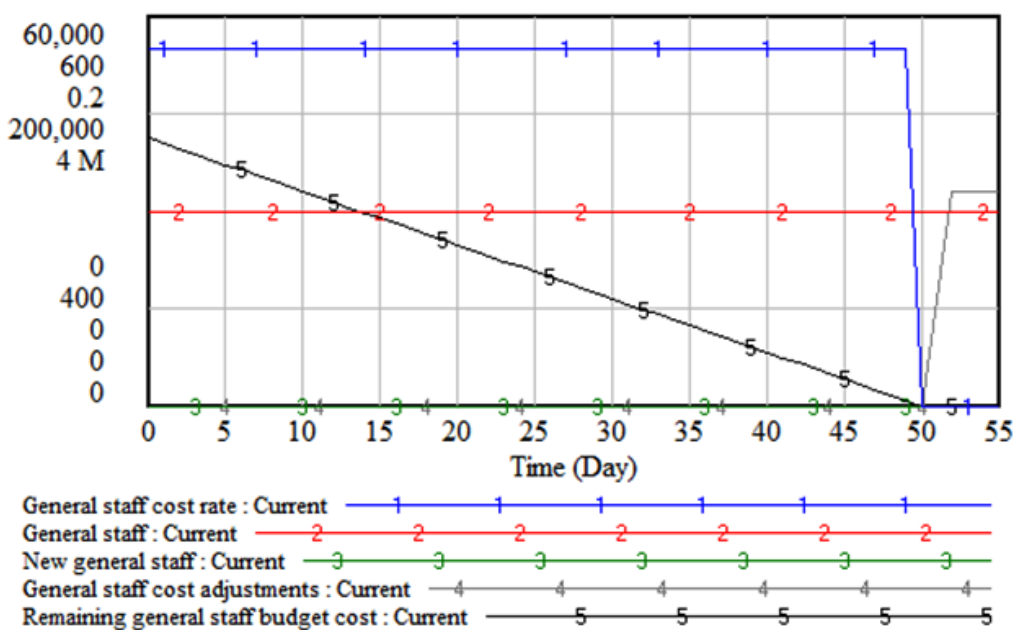

Fig. (10). Simulated result at $30^{\text {th }}$ day with key staff risk element $=0.5$, deadline pressure index $=1.1$.

The project was completed in 50 days, and we can find out in this figure that the quantities of key personnel and general personnel reach respectively a maximum of 62 and a maximum of 612 , and the labor charges increase 0.87 of ten thousand yuan and 6.13 of it.

This part demonstrates the key staff risk element occurred at 30th, the key staff risk element index was 0.5 , and the project was not allowed to be postponed. This is confirmed by the simulation results in Fig. (9).

The construction was too hard to keep acceptability criteria, and 1396.5 units rework quantity were produced. The project manager would enhance the speed of construction, through increase in key staff and the general staff.

The project was completed in 50 days, and we can find out in this figure that the quantities of key personnel and general personnel reach respectively a maximum of 55 and a maximum of 548 , and the labor charges increase 0.36 of ten thousand yuan and 8.17 of it.

The Fig. (10) presents how the change with the key staff risk element occurred at 30th, while the key staff risk element index was 0.5 , and the time can delay the planned construction period of $10 \%$. The construction was too hard to keep acceptability criteria, and 1396.5 units rework quantity were produced. The project manager would enhance the speed of construction, through increase in key staff and the general staff.

The project was completed in 52 days, and we can find out in this figure that the quantities of key personnel and general personnel reach respectively a maximum of 50 and a maximum of 500 , and the labor charges increase 0.7 of ten thousand yuan and 11 of it.

The Fig. (11) shows that the key staff risk element and general staff risk element occurred at 30th, the two parameter of the model were all set to 0.5 , and the time can delay the planned construction period of $50 \%$. The construction was forced to build slowly, in the key staff and general staff part of the loss. Because can delay, the project manager would not increase in key staff and the general staff. The project was completed in 69 days, and the labor charges are not increase.

\section{CONCLUSION}

$V i a$ the process of transmission, the human risk element generated in the construction will have influence on the quantities, cost and duration of the project. Depending on these circumstances, in this paper we develop a SD model of the risk element transmission which simulates the affected scope and depth of the project by the human risk element. We can draw following aspects of conclusions by simulating. 

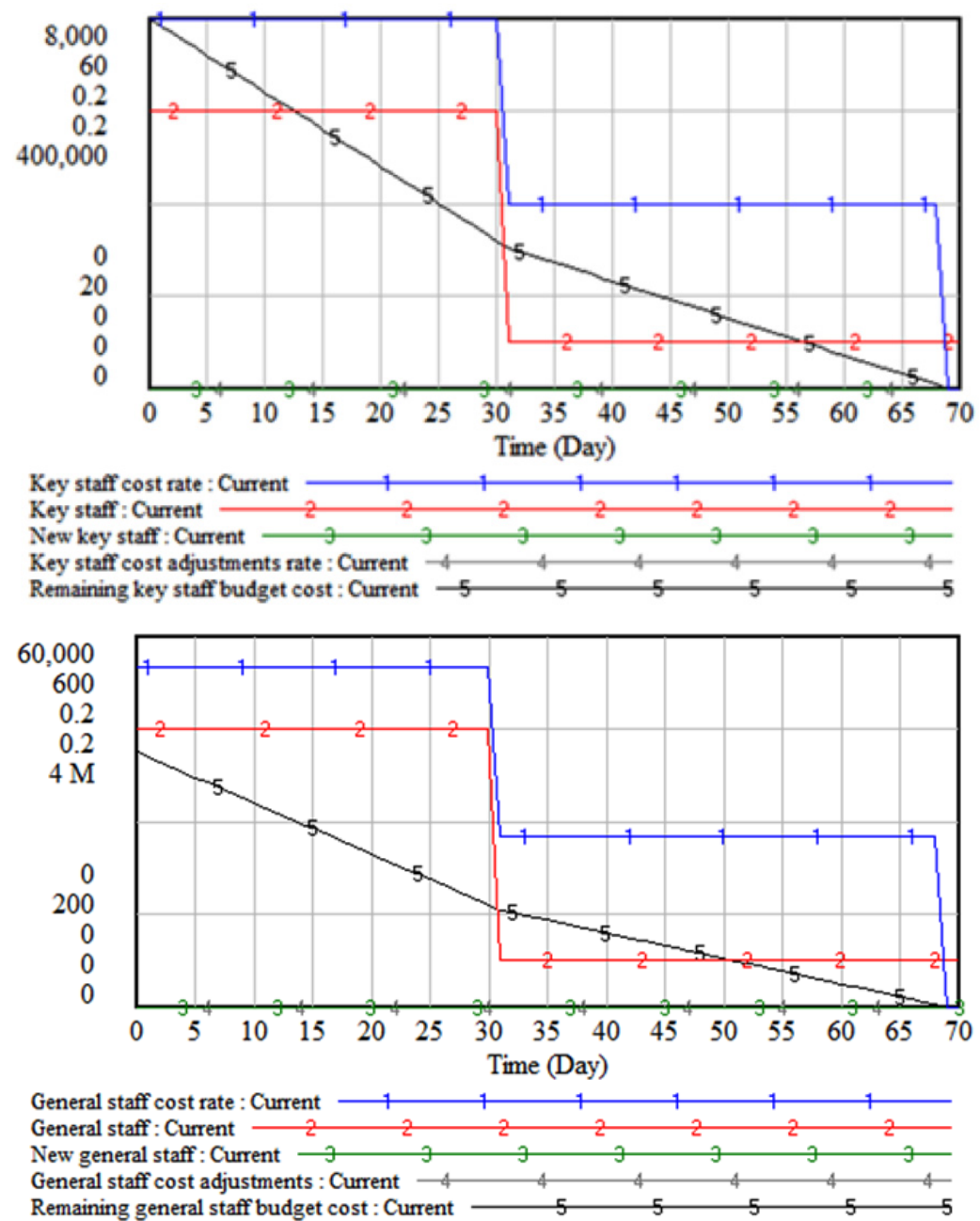

Fig. (11). Simulated result at $30^{\text {th }}$ day with key staff risk element $=0.5$, general staff risk element $=0.5$, deadline pressure index $=1.5$.

1) The risk element transmission theory was introduced into the process that how the human risks impact the construction project and transfers, can carry on quantitative analysis on the procedure and level.

2) The schedule will disrupt while the human risk element occurs. In order not to delay, it will cause more serious cost overruns if enhance the speed of construction through increase in key staff and the general staff.

3 ) If the risk occur too late, the remaining quantity not many. Appropriate extension is more cost savings, while to increase the number of personnel cannot be completed on schedule.

4) Key staff and general staff ratio will be destroyed as the key staff risk element was produced. During increase technical staff, if not to reduce the speed of construction, will make more rework quantities, and form more waste.

5) When the general staff risk occurs, the proportion of key staff and general staff more than standard, key staff workload is not saturated, while the general staff increase.

As future research directions, we may analyze the multiple stacking transfer process and the effect of human risk element in one construction project, and other human risk element which can indirect impact the project quality and construction speed.

\section{CONFLICT OF INTEREST}

The authors confirm that this article content has no conflict of interest.

\section{ACKNOWLEDGEMENTS}

This research is partially funded by the National Natural Science Foundation of China (71271084 and 71071054), the Fundamental Research Funds for the Central Universities (2014XS55) and the Project for The Beijing's EnterpriseAcademics-Research Co-Culture Post-Graduate.

\section{REFERENCES}

[1] M. Park, and F. Peña-Mora, "Dynamic change management for construction: introducing the change cycle into model-based project management," System Dynamics Review, vol. 19, pp. 213-242, Mar. 2003.

[2] M.Z. Abd Majid, and R. McCaffer, "Factors of non-excusable delays that influence contractors' performance," Journal of Management in Engineering, vol. 14, pp. 42-49, Mar. 1998.

[3] A. Touran, P.J. Bolster, and S.W. Thayer, Risk Assessment in Fixed Guideway Transit System Construction, US Federal Transit Administration, University Research and Training Program, 1994, pp. 123-124. 
[4] J.H.M. Tah, A. Thorpe, and R. McCaffer, "Contractor project risks contingency allocation using linguistic approximation," Computing Systems in Engineering, vol. 4, pp. 281-293, Feb. 1993.

[5] J.D. Sterman, System Dynamics Modeling for Project Management, Unpublished manuscript, Cambridge, MA, Mar, 1992.

[6] General Accounting Office, Transportation Infrastructure: Cost and Oversight Issues on Major Highway and Bridge Projects, GAO-02-702T, Washington, DC, 2002.

[7] M. Latham, Constructing the Team, HMSO, London, 1994.

[8] F.J. Bromilow, Measurement and Scheduling of Construction Time and Cost Performance in Building Industry, The Chartered Builder, Oct. 1974.

[9] B. Flyvbjerg, N. Bruzelius, and W. Rothengatter, Megaprojects and Risk: An Anatomy of Ambition, Cambridge University Press, US, 2003.

[10] J.T. Reason, Human Error, Cambridge University Press, US, 1990.

[11] D. Wang, and L. Wang, "Using analytic network process to analyze problems for implementing turn-key construction projects in Taiwan", Journal of Central South University of Technology, vol. 18, pp. 558-567, 2011.

[12] K. Barker, and Y.Y. Haimes, "Assessing uncertainy in extreme events: applications to risk-based decision making in interdependent infrastructure sectors," Reliability Engineering and System Safety, vol. 94, pp. 819-829, 2009.

[13] A. Balbás, R. Balbás, and S. Mayoral, "Portfolio choice and optimal hedging with general risk functions: a simplex-like algorithm", European Journal of Operational Research, vol. 192, pp. 603-620, 2009.

[14] M. De Beule, E. Maes, O. De Winter, W. Vanlaere, and R. Van Impe, "Artificial neural networks and risk stratification: a promising combination," Mathematical and Computer Modelling, vol. 46, pp. 88-94, Feb. 2007.

[15] C. Perkgoz, A. Azaron, H. Katagiri, K. Kato, and M. Sakawa, "A multi-objective lead time control problem in multi-stage assembly systems using genetic algorithms," European Journal of Operational Research, vol. 180, pp. 292-308, Jan. 2007.

[16] S.K. Au, Z. Wang, and S. Lo, "Compartment fire risk analysis by advanced Monte Carlo simulation," Engineering Structures, vol. 29, pp. 2381-2390, Sep. 2007.
[17] F. Li, J. Huang, G. Zeng, J. Liang, and X. Wang, "Multimedia health risk assessment: a case study of scenario-uncertainty," Journal of Central South University, vol. 19, pp. 2901-2909, Oct. 2012

[18] J. Peng, M. Wen, and G. Xie, "Coordinated dynamic mission planning scheme for intelligent multi-agent systems," Journal of Central South University, vol. 19, pp. 3170-3179, Nov. 2012

[19] E.W.K. Tsang, and S.A. Zahra, "Organizational unlearning," $\mathrm{Hu}$ man Relations, vol. 61, pp. 1435-1462, Oct. 2008.

[20] P.E.D. Love, D.J. Edwards, Z. Irani, and D.H.T. Walker, "Project pathogens: the anatomy of omission errors in construction and resource engineering projects," IEEE Transactions on Engineering Management, vol. 56, pp. 425-435, Mar. 2009

[21] D. Vlachos, P. Georgiadis, and E. Iakovou, "A system dynamics model for dynamic capacity planning of remanufacturing in closedloop supply chains," Computers \& Operations Research, vol. 34, pp. 367-394, Feb. 2007.

[22] M. Peng, Y. Peng, and H. Chen, "Post-seismic supply chain risk management: A system dynamics disruption analysis approach for inventory and logistics planning," Computers \& Operations Research, vol. 42, pp. 14-24, Mar. 2014.

[23] M. Mecoli, V. De Angelis, and S.C. Brailsford, "Using system dynamics to evaluate control strategies for mosquito-borne diseases spread by human travel," Computers \& Operations Research, vol. 40, pp. 2219-2228, Sep. 2013.

[24] C.B. Li, and X. Li, "The analytic model and its application of generalized project risk elements transmission," Journal of Computational Information Systems, vol. 4, pp. 671-678, Feb. 2008.

[25] C. Li, and K. Wang, "Research on the risk element transmission analytic model of construction Network Planning Project," Chinese Journal of Management Science, vol. 15, pp. 108-113, Nov. 2007.

[26] C. Li, and K. Wang, "A new grey forecasting model based on BP neural network and Markov chain", Journal of Central South University of Technology, vol. 14, pp. 136-142, May. 2007.

[27] C. Li, and J. Wang, "Model of generic project risk element transmission theory based on data mining," Journal of Central South University of Technology, vol. 15, pp. 26-32, Jan. 2008.

\begin{tabular}{lll}
\hline Received: September 16, 2014 & Revised: December 23, 2014 & Accepted: December 31, 2014
\end{tabular}

(C) Cunbin et al.; Licensee Bentham Open.

This is an open access article licensed under the terms of the Creative Commons Attribution Non-Commercial License (http://creativecommons.org/licenses/by-nc/3.0/) which permits unrestricted, non-commercial use, distribution and reproduction in any medium, provided the work is properly cited. 